Kumawula, Vol. 3, No.1, April 2020, Hal 48 - 59 DOI:http://10.24198/kumawula.v3i1.24820

ISSN 2620-844X (online)

Tersedia online di http://jurnal.unpad.ac.id/kumawula/issue/view

\title{
PENINGKATAN SENSITIVITAS KEPEMIMPINAN LOKAL DALAM PENGELOLAAN SUNGAI CITARUM MELALUI TEKNIK PARTICIPATORY RURAL APPRAISAL (PRA) DI DESA RANCAMANYAR
}

\author{
Rudi Saprudin Darwis ${ }^{1}$, Risna Resnawaty ${ }^{2}$, Eva Nuriyah ${ }^{3}$ \\ ${ }^{1,2,3}$ Departemen Kesejahteraan Sosial, Fakultas Ilmu Sosial dan Ilmu Politik, Universitas Padjadjaran \\ 1rudi.darwis@unpad.ac.id, ²risna.resnawaty@unpad.ac.id, 3enuriyah@yahoo.co.id
}

\begin{abstract}
ABSTRAK
Pemimpin lokal merupakan stakeholder yang sangat strategis dalam pengelolaan lingkungan. Kekuasaan dan kewenangan yang dimilikinya dapat mempengaruhi upaya pengelolaan lingkungan dan masyarakatnya. Untuk mengoptimalkan peran pemimpin lokal tersebut perlu adanya pengingkatan sensitivitas dalam diri pemimpin lokal terhadap kondisi sosial dan fisik lingkungan masyarakat yang menjadi tanggung jawabnya. Metode yang digunakan untuk meningkatkan sensitivitas pemimpin lokal adalah melalui workshop sensitivitas dengan menggunakan teknik Participatory Rural Appraisal (PRA) dalam konteks pengelolaan Daerah Aliran Sungai (DAS) Citarum di Desa Rancamanyar, Kecamatan Baleendah, Kabupaten Bandung. Pemimpin lokal yang hadir dalam workshop terdiri dari kepala desa, sekretaris desa, ketua dan para anggota Badan Perwakilan Desa (BPD), ketua dan anggota PKK, ketua RW yang wilayahnya berada di sekitar DAS Citarum, tokoh agama, dan tokoh masyarakat lainnya. Hasil workshop menunjukkan para peserta dapat berperan serta dalam proses PRA dan menunjukkan pengetahuan yang baik mengenai wilayahnya. Proses yang dilaksanakan dalam workshop mendorong para pemimpin lokal untuk lebih mencermati situasi dan kondisi masyarakat dan lingkungannya. Peserta dapat melihat adanya sinergi dengan peningakatan kesadaran mereka atas status dan peran yang disandangnya. Selain untuk pengembangan potensi yang ada di masyarakat, pengelolaan lingkungan juga mencakup tentang penanganan bencana yang dapat mengancam keselamatan masyarakat di sekitar aliran sungai citarum khususnya Desa Rancamanyar, sehingga dapat dikatakan langkah peningkatan sensitivitas para pemimpin lokal ini adalah sebuah langkah awal untuk membangun sistem pengelolaan sungai yang berbasis masyarakat.
\end{abstract}

Kata kunci: sensitivitas, pemimpin lokal, stakeholder, pengelolaan sungai citarum, dan masyarakat

\begin{abstract}
In the categorization of stakeholders, local leaders can be said to be stakeholders from the elements of society. Upon the predicate of these stakeholders, local leaders are the spearhead of the community that can be optimized in the steps of developing the potential of the local community. To optimize the role of local leaders, it is necessary to increase sensitivity in local leaders towards the social and physical conditions of the community they are responsible for. The method used to increase the sensitivity of local leaders is through sensitivity workshops using Participatory Rural Appraisal (PRA) techniques in the context of the management of the Citarum River Watershed in Rancamanyar Village, Baleendah District, Bandung Regency. The local leaders present at the workshop consisted of the village head, village secretary, chairperson and members of the Village Representative Body (BPD), chairperson and members of the PKK, RW leader whose area is around the Citarum watershed, religious leaders, and other community leaders. The results of the workshop showed that participants
\end{abstract}


could participate in the PRA process and show good knowledge about the area. The process carried out in the workshop encouraged local leaders to pay more close attention to the situation and condition of the community and its environment. Participants can see a synergy with increasing their awareness of the status and role they assume. In addition to developing the potential that exists in the community, environmental management also includes handling disasters that can threaten the safety of the community around the Citarum river basin, especially Rancamanyar Village, so it can be said that the step to increase the sensitivity of local leaders is a first step to building a river management system that community-based.

Keywords: sensitivity, local leader, stakeholder, management of citarum river, and society

\section{PENDAHULUAN}

Sungai citarum menjadi salah satu fokus perhatian Pemerintah Pusat semenjak diterbitkannya Perpres No. 15 tahun 2018 tentang Percepatan Pengendalian Pencemaran DAS (Daerah Aliran Sungai) Citarum yang menugaskan Tim Satgas dari satuan TNI menjadi tim penggerak untuk menertibkan dan membersihkan sungai citarum, sekaligus menegaskan Satgas menjadi pihak yang paling berwenang dalam pengelolaan dan penertiban sungai citarum selama tujuh tahun melalui program Citarum Harum. Dalam sudut pandang lain, pemberian kewenangan Satgas khususnya yang terjadi di sektor 7 citarum harum yang ada di Kecamatan Baleendah dalam program citarum harum juga terdapat aspek yang kurang diperhatikan, yaitu keterlibatan masyarakat Desa Rancamanyar, Kecamatan Baleendah secara langsung dalam pemulihan kondisi sungai citarum. Sebagai pihak yang merasakan langsung, masyarakat lokal menjadi pihak yang paling paham mengenai kondisi lingkungan fisik maupun sosial di sekitar wilayah sungai citarum.

Dalam kesatuan masyarakat lokal Desa Rancamanyar, secara struktural akan ditemukan keberadaan pihak-pihak atau tokoh-tokoh yang dijadikan sebagai pemimpin lokal. Pemimpin lokal dapat dikatakan sebagai salah satu stakeholder dari unsur masyarakat (Rubin dan Rubin 1992). Para pemimpin lokal sebagai stakeholder dari unsur masyarakat adalah sebagai pihak yang menjadi penghubung antara pihak dari luar dari masyarakat dan masyarakat itu sendiri, seperti Kepala Desa, Ketua RT dan RW, tokoh penggiat alam, tokoh ulama, tokoh masyarakat, ibu-ibu PKK, Posyandu, dan lainnya. Meraka adalah tokoh-tokoh di Desa Rancamanyar yang menjadi pemimpin formal maupun informal bagi masyarakatnya.

Di Desa Rancamanyar, para pemimpin lokal itu memiliki kedudukan yang strategis untuk mempengaruhi masyarakat. Pemikiran, pandangan, sikap, maupun tindakan mereka dalam kerangka pembangunan masih didengar dan diperhatikan masyarakat. Masyarakat cukup 
percaya kepada para tokoh ini untuk mewakili dan mengatasnamakan masyarakat dalam penyelenggaraan program pembangunan seperti Program Citarum Harum.

Karena itu, para pemimpin lokal perlu memiliki kepekaan yang baik mengenai kondisi yang ada pada lingkungan sosial maupun lingkungan fisik dari masyarakatnya. Untuk memaksimalkan peran besar yang dimiliki para pemimpin lokal tersebut, maka perlu dilakukan peningkatan sensitivitas kepada para pemimpin lokal yang bertujuan untuk memaksimalkan potensi yang dimiliki oleh para pemimpin lokal, dan nantinya akan mampu mendorong masyarakat untuk berperan aktif dalam pengelolaan Sungai Citarum.

Sensitivitas yang dimaksudkan adalah kepekaan seseorang terhadap kondisi sosial yang ada di sekitarnya, hal tersebut berhubungan dengan self awareness atau kesadaran diri yang dimiliki oleh seorang atas pengalaman dan nilai yang diyakini terhadap status yang dimiliki dan peran yang harus dijalankan (Cooley dalam Ostrow:1990). Kepekaan seseorang dapat ditingkatkan melalui kegiatan tertentu seperti pelatihan ataupun workshop. Karena itu, sensitivitas pemimpin lokal di Desa Rancamanyar ditingkatkan melalui kegiatan workshop.

Tujuan diselenggarakannya workshop sensitivitas kepemimpinan lokal ini adalah untuk meningkatkan self awareness dalam diri para pemimpin yang nantinya akan berdampak pada peningkatan sensitivitas para pemimpin lokal di Desa Rancamanyar. Dalam kasus ini sensitivitas seorang pemimpin lokal dibutuhkan untuk jeli dalam melihat potensi yang bisa dimanfaatkan dan resiko yang ada di tengah-tengah masyarakat. Dengan tingkat sensitivitas yang tinggi seorang pemimpin akan mampu melakukan tindakan preventif yang dapat dilakukan dalam pengelolaan sungai citarum yang berbasis masyarakat, baik dalam memaksimalkan potensi lokal maupun pencegahan terhadap resiko masalah dan bencana yang mungkin dialami oleh masyarakat.

Pengelolaan yang dimaksudkan dalam hal ini bukan hanya tentang bagaimana menciptakan sungai citarum yang bersih secara fisik, tetapi juga untuk memaksimalkan potensi yang dapat dimanfaatkan dari kehadiran sungai citarum dan potensi bencana yang dapat dialami dengan adanya sungai citarum. Tujuan peningkatan sensitivitas adalah untuk meningkatkan kesadaran pemimpin akan kedua hal tersebut, yakni potensi dan resiko bencana yang kemungkinan besar akan dialami oleh masyarakat dan mampu menciptakan pengelolaan sungai citarum berbasis masyarakat.

\section{METODE}


Dalam rangka memantapkan Program Pengelolaan Bencana Berbasis Masyarakat atau yang dikenal dengan Community Based Risk Management (CBDRM), diperlukan suatu teknik perencanaan yang matang dengan melibatkan masyarakat sebagai subjek pengelola mitigasi bencana dan pembuatan keputusan. Pemahaman Pengkajian/Penjajagan Partisipatif Resiko Bencana adalah suatu metode pendekatan untuk mempelajari kondisi daerah dan kehidupan dari, dengan dan oleh masyarakat sendiri. Kegiatan PRA bukanlah pelibatan masyarakat dalam sebuah paket perencanaan suatu program saja, melainkan harus sampai tingkat pelaksanaan, monitoring, dan evaluasi.

Intisari dan prinsip Participatory Risk Assessment (PRA) diambil dari Metode Participatory Rural Appraisal (PRA). Secara bahasa PRA berarti memahami desa secara partisipatif. Adapun secara istilah adalah sekumpulan pendekatan dan metode yang mendorong masyarakat desa untuk berpartisipasi aktif dalam meningkatkan dan menganalisis pengetahuan mereka mengenai kondisi kehidupan mereka sendiri, agar mereka dapat membuat rencana tindakan yang layak. Proses kajian secara partisipatif dalam Participatory Risk Assessment mengadopsi teknik-teknik Participatory Rural Appraisal (PRA), yang biasanya dilakukan untuk area yang lebih luas dan untuk hal-hal yang bersifat umum (General). Sedangkan Participatory Risk Assessment ini mencakup area yang lebih terbatas dan untuk aspek khusus (topikal), yaitu mengenai segala aspek kebencanaan. Oleh karena itu dapat dikatakan bahwa Participatory Risk Assessment disini adalah Participatory Rural Appraisal (PRA) dalam konteks kebencanaan.

Pada pelaksanaan Participatory Risk Assessment (PRA) masyarakat difasilitasi oleh orang luar; seperti peneliti, Kelompok Kerja (Pokja), Tenaga Pendamping Masyarakat (TPM), dan Fasilitator Lokal sebagai jembatan antara orang luar dan orang dalam (masyarakat) itu sendiri. Hasil yang diharapkan dari kegiatan ini adalah masyarakat mampu menganalisis kondisi kehidupannya yang mencakup potensi dan permasalahan yang ada di desanya, kemudian dapat menyusun program berdasarkan potensi yang ada baik itu potensi Sumberdaya Alam (SDA) maupun potensi Sumberdaya Manusia (SDM) dalam menangani masalah bencana.

Menurut Conyers (1984), memposisikan masyarakat sebagai pelaku pembangunan adalah penting karena: Pertama, masyarakat merupakan sumber informasi mengenai kondisi, kebutuhan dan sikap masyarakat setempat, sehingga tanpa kehadirannya program pembangunan dan proyek-proyek akan gagal karena tidak tepat penanganannya; Kedua, 
masyarakat akan lebih mempercayai proyek atau program pembangunan jika mengetahui seluk beluk proyek tersebut; Ketiga, merupakan hak masyarakat untuk dilibatkan dalam pembangunan masyarakat mereka sendiri.

Output kegiatan Participatory Risk Assessment dipadukan dengan data awal (data sekunder) adalah berupa Profil Komunitas Daerah Rawan Bencana yang mencakup profil kerentanan, bahaya dan resiko serta kapasitas/kemampuan individu, keluarga dan kelompok/komunitas dalam mengurangi resiko bencana. Manfaat yang bisa diambil dari proses kegiatan Participatory Risk Assessment disamping untuk upaya pemberdayaan masyarakat, juga outputnya profil resiko, bahaya, kerentanan dan kapasitas komunitas daerah rawan bencana ini bisa dipakai oleh lembaga donor, pemerintah, atau swasta dalam membuat dan mengembangkan suatu program pengurangan resiko bencana di Daerah Rawan Bencana yang bersangkutan.

Mengingat bahwa yang dimaksud dengan Participatory Risk Assessment adalah Participatory Rural Appraisal (PRA) dalam konteks kegiatan kebencanaan, maka prinsip-prinsip Participatory Risk Assessment sama dengan prinsip-prinsip PRA. Pendekatan Participatory Risk Assessment lebih menekankan pada proses pelaksanaan kajian secara partisipatif (bukan eksploratif). Penekanan pada proses yang partisipatif inilah yang menjadi paradigma Participatory Risk Assessment. Paradigma ini akan menjadi lebih jelas dengan memahami prinsip-prinsip Participatory Risk Assessment sebagai berikut:

1. Belajar dari masyarakat. Prinsip yang paling mendasar dalam Participatory Risk Assessment adalah prinsip bahwa Participatory Risk Assessment adalah dari, oleh dan untuk masyarakat.

2. Orang luar (peneliti, tenaga ahli, petugas) sebagai fasilitator, orang dalam (masyarakat) sebagai pelaku. Participatory Risk Assessment menempatkan masyarakat sebagai pelaku utama, sedangkan orang luar sebagai fasilitator.

3. Saling belajar, saling berbagi pengalaman. Walaupun ada pengakuan atas pengalaman dan pengetahuan tradisional masyarakat, bukan berarti masyarakat selamanya benar dan dibiarkan tidak berubah. Demikian juga pengetahuan “modern” yang diperkenalkan oleh orang luar tidak selalu dapat memecahkan masalah mereka. 
4. Santai dan Informal serta kekeluargaan. Kegiatan Participatory Risk Assessment hendaknya diselenggarakan dalam suasana yang bersifat luwes, tidak memaksa, terbuka, dan informal. Hal tersebut bertujuan agar keterbukaan informasi berjalan dengan lancar dan terbuka antara fasilitator dan masyarakat.

5. Keterlibatan semua unsur masyarakat. Setiap unsur baik masyarakat secara menyeluruh maupun pihak-pihak yang dipercaya oleh masyarakat sebagai pihak yang mewakili kehadiran masyarakat dilibatkan dalam pelaksanaan PRA.

6. Menghargai perbedaan. Mengingat peserta Participatory Risk Assessment adalah masyarakat yang heterogen (berbagai macam golongan atau tipe), tentu akan muncul berbagai pendapat atau pandangan. Oleh karena itu, semangat saling menghargai harus ditekankan.

7. Triangulasi. Untuk mendapatkan informasi yang diharapkan dan sesuai dengan kondisi yang sebenarnya, dapat digunakan triangulasi yang merupakan bentuk "pemeriksaan dan pemeriksaan ulang” (check and recheck).

8. Mengoptimalkan hasil. Pelaksanaan kegiatan Participatory Risk Assessment memerlukan waktu, tenaga, biaya, kesabaran, ketelitian yang tidak sedikit dari para fasilitator dan masyarakat, maka kegiatan Participatory Risk Assessment hendaknya mengoptimalkan kegiatannya dengan mengkaji hal-hal yang dianggap paling penting secara optimal.

9. Belajar dari Kesalahan. Melakukan kesalahan, yang sering dianggap tidak wajar, dalam PRA adalah sesuatu yang wajar, yang penting bukanlah kesempurnaan dalam penerapanyang tentu sukar dicapai-, tetapi penerapan sebaik-baiknya sesuai dengan kemampuan.

10. Orientasi Praktis. PRA berorentasi pada pemecahan masalah dan pengembangan program. Untuk itu dibutuhkan informasi yang relevan (yang ada kaitannya dengan program) dan memadai.

11. Berkelanjutan. Kegiatan PRA bukanlah sebuah "paket kegiatan" yang selesai setelah penggalian informasi dianggap cukup, tetapi ada rendana tindak lanjut yang akan dilaksanakan setelah penggalian informasi selesai.

Melalui teknik PRA ini para pemimpin lokal di Desa Rancamanyar akan diarahkan untuk lebih peka terhadap potensi yang dimiliki dan juga resiko yang hadir diantara masyarakat Desa Rancamanyar. Para pemimpin lokal akan diajak untuk menyadari potensi-potensi yang dimiliki dan dapat dioptimalkan dalam pengelolaan sungai citarum yang nantinya akan 
berbasis masyarakat dalam pengelolaannya, baik dalam pemanfaatan potensi maupun pengurangan dan penanggulangan resiko bencana.

\section{HASIL DAN PEMBAHASAN}

Kegiatan workshop peningkatan sensitivitas pemimpin lokal di Desa Rancamanyar diawali dengan pemberian materi dan diskusi mengenai dinamika kepemimpinan lokal yang diikuti oleh seluruh peserta dengan dibantu fasilitator. Para peserta antusias dalam menyampaikan pendapat mereka dalam proses diskusi yang berlangsung. Beberapa tokoh dari perwakilan RT, RW, Pemerintah Desa dan BPD masing-masing berpendapat mengenai materi yang dipaparkan terkait sensitivitas lokal, peserta juga menjelaskan kepada fasilitator mengenai kondisi aktual yang sedang terjadi di Desa Rancamanyar dan berdampak pada kehidupan masyarakat.

Setelah diskusi selesai fasilitator melanjutkan kegiatan pada pelaksanaan PRA bersama dengan para pemimpin lokal Desa Rancamanyar. Teknik PRA yang digunakan melalui teknik diagram ven, hubungan kelembagaan untuk memetakan lembaga-lembaga apa saja yang ada di Desa Rancamanyar dan memetakan hubungan kedekatan lembaga-lembaga tersebut dengan masyarakat. Teknik ini bertujuan untuk melihat lembaga apa saja yang berperan besar dan memiliki kedekatan yang intim dengan masyarakat, nantinya hasil dari pemetaan lembaga tersebut akan menggambarkan lembaga-lembaga mana saja yang dapat dimaksimalkan perannya dalam menciptakan pengelolaan sungai citarum yang berbasis masyarakat.

Pada pelaksanaan metode PRA bersama dengan para pemimpin lokal Desa Rancamanyar yang masih bertahan sampai dengan tahap diskusi yaitu berjumlah lima belas orang, diantaranya terdiri dari Kepala Desa, Sekertaris Desa, para Ketua RT dan RW, Kader PKK, Kader Posyandu, dan para penggiat alam. Pelaksanaan PRA dimulai oleh fasilitator yang mengajak warga untuk mengidentifikasi lembaga-lembaga apa saja yang terdapat di Desa Rancamanyar. Lembaga-lembaga tersebut terdiri dari:

PKK; 2) Bumdes; 3) BPD; 4) LSM; 5) LPM; 6) MUI; 7) Karang Taruna; 8) RT; 9) RW; 10) Ecovillage; 11) Puskesos; 12) Komunitas Gowes; 13) Kepala Desa; 14) Pemerintah Desa; 15) Kecamatan; 16) Dinas Lingkungan Hidup Kabupaten; 17) KUA; 18) Pemerintah Kabupaten; 19) BBWS; 20) PJT 2; 21) Puskesmas; 22) TNI; 23) POLRI; 24) BPLHD; 25) Disperintan.

Gambar 1 merupakan visualisasi dari hasil pemetaan identifikasi besaran peran tiap lembaga dan jarak dari kehadiran lembaga-lembaga tersebut terhadap peran yang dirasakan oleh 
masyarakat Desa Rancamanyar. Lembaga-lembaga tersebut adalah lembaga-lembaga yang dirasakan kehadirannya di tengah-tengah masyarakat dan memiliki peran di masyarakat Desa Rancamanyar. Tidak semua lembaga dapat terpetakan dalam diagram tersebut, karena tidak semua lembaga dapat dirasakan kehadirannya dan perannya di tengah-tengah masyrakat Desa Rancamanyar.

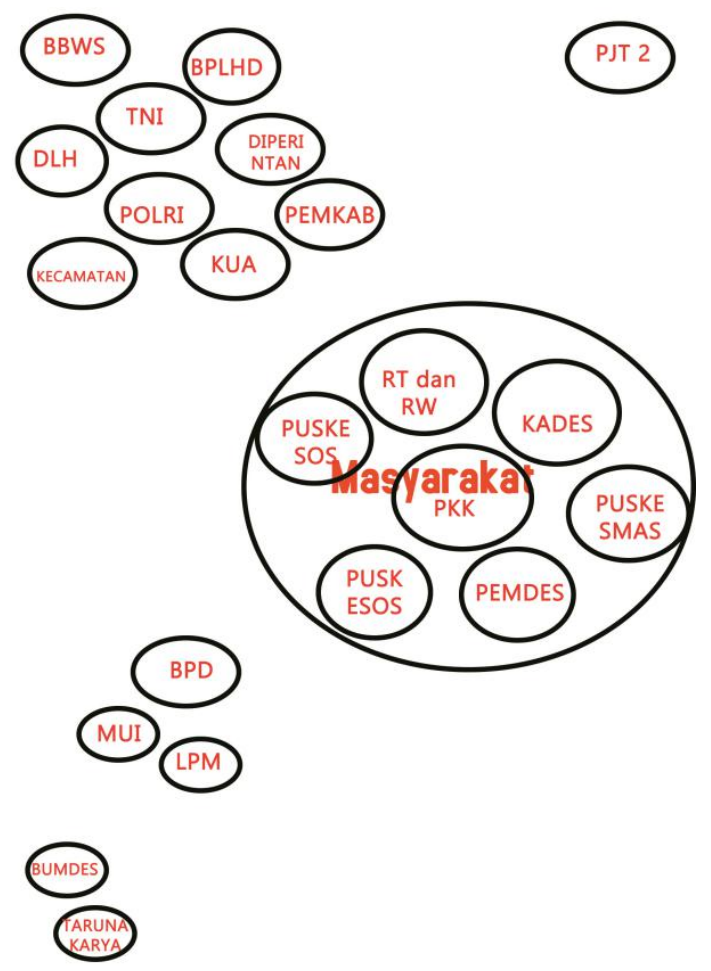

Gambar 1 Diagram Ven Kelembagaan Lokal

Setelah peserta mampu untuk mengidentifikasi lembaga-lembaga yang ada di Desa Rancamanyar, berikutnya fasilitator mengarahkan peserta untuk menentukan lembaga mana saja yang memiliki peran besar bagi masyarakat desa dan dekat kehadirannya di tengahtengah masyarakat Desa Rancamanyar. Penentuan lembaga-lembaga tersebut melalui metode scoring atau penentuan poin besaran peran lembaga dan besaran jarak antara lembaga dan masyarakat yang berkisar antara 1 s.d. 7. Melalui scoring tersebut nantinya akan menggambarkan besarnya peran lembaga terhadap masyarakat desa dan jarak antara lembaga dengan masyarakat. Semakin besar poin sebuah lembaga, maka semakin besar juga perannya bagi masyarakat desa, semakin kecil jarak antara lembaga dan masyarakat, maka kehadiran lembaga tersebut akan semakin dirasakan kehadirannya oleh masyarakat. Berikut ini adalah 
lembaga-lembaga yang menurut peserta memiliki peran besar dan dekat kahadirannya bagi masyarakat Desa Rancamanyar:

1) Kepala Desa; 2) Pemerintah Desa: 3) Puskesmas; 4) RT dan RW; 5) Puskesos; dan 6) PKK.

Tujuh lembaga tersebut adalah lembaga-lembaga yang menurut peserta memiliki peran besar bagi masyarakat desa dan kehadirannya sangat dekat dan dirasakan oleh masyarakat desa, tetapi fasilitator juga mengarahkan peserta untuk memberikan catatan terhadap kehadiran lembaga-lembaga tersebut mengenai kekurangan atau saran untuk lembaga tersebut, berikut catatannya:

1. Kepala Desa

“Lanjutkan kinerja Baiknya”. peserta dari unsur PKK, RT, dan RW merasa Kepala Desa selama menjabat cukup menjalankan perannya dengan dan dekat dengan masyarakat Desa Rancamanyar, sehingga peserta ingin Kepala Desa mempertahankan kinerjanya dan meningkatkan untuk lebih baik lagi.

\section{Pemerintah Desa}

“Lanjutkan kinerja Baiknya”. sama halnya dengan Kepala Desa peserta juga merasa Pemerintah Desa selama menjabat cukup menjalankan perannya dengan dan dekat dengan masyarakat Desa Rancamanyar, sehingga peserta ingin Kepala Desa mempertahankan kinerjanya dan meningkatkan untuk lebih baik lagi.

\section{Puskesmas}

"Pelayanan ditingkatkan dan lebih terbuka”. Peserta merasa Puskesmas selama ini masih kurang maksimal dan terbuka dalam memberikan pelayanan kepada masyarakat, karena peserta merasa masih sulit untuk menggunakan fasilitas-fasilitas yang ada di Puskesmas dan hanya orang-orang tertentu yang memiliki akses cepat dalam menerima pelayanan dari Puskesmas, salah satu peserta dari unsur BPD berujar "Puskesmas saat ini seperti dimiliki oleh orang-orang yang mengurus puskesmas, pelayanan yang maksimal hanya diperuntukkan untuk orang-orang tertentu, padahal seharusnya semua unsur masyarakat berhak mendapatkan pelayanan yang maksimal dari Puskesmas”.

4. RT (Rukun Tetangga) dan RW (Rukun Warga) 
“Aktif ke desa dan tertib administrasi”. Peserta menginginkan setiap kepala RT dan RW untuk aktif berkegiatan di desa, agar segala informasi yang bersumber dari desa dan penting bagi masyarakat dapat tersalurkan dengan baik dan cepat kepada masyarakat.

\section{Puskesos}

"Harus lebih aktif menjalankan sosialisasi kepada masyarakat”. Peserta dari unsur Pemerintah Desa Rancamanyar, yaitu Sekretaris Desa merasa sebenarnya Puskesos memiliki peran besar bagi masyarakat, tetapi masih banyak masyarakat yang belum mengetahui tentang Puskesos itu sendiri, sehingga Puskesos harus meningkatkan kegiatann sosialisasi kepada masyarakat secara langsung.

\section{PKK}

“Dalami rencana strategis desa”. Peserta dari unsur BPD menilai selama ini sebenarnya PKK memiliki peran besar bagi masyarakat Desa Rancamanyar, tetapi PKK kurang bersinergi dengan rencana strategis desa dalam menjalankan perannya di masyarakat. Oleh karena itu, peserta menginginkan PKK lebih bersinergi lagi dengan rencana strategis desa agar kedepannya peran yang dilakukan PKK kepada masyarakat benar-benar sesuai dengan rencana strategis desa.

Dengan catatan-catatan yang mendetil pada setiap lembaga dapat menjadi bahan evaluasi bagi setiap lembaga untuk meningkatkan performanya dalam memberikan pelayanan kepada masyarakat Desa Rancamanayar.

Kemampuan menafsirkan berbagai situasi sosial yang ada pada lingkungan sosialnya menunjukkan sensitivitas para pemimpin lokal. Sebagaimana dinyatakan Riggio (2008) bahwa sensitivitas sosial menunjukkan keterampilan dalam menafsirkan komunikasi verbal dari orang lain; kemampuan untuk memahami situasi sosial, norma sosial, dan peran. Berdasarkan hasil penafsiran tersebut, interaksi dan perlakuan diantara para tokoh dapat dikembangkan.

Setelah mengidentifikasi dan menentukan lembaga-lembaga mana saja yang memiliki peran besar bagi masyarakat desa dan dirasakan kehadirannya oleh masyarakat Desa Rancamanyar. Fasilitator mengarahkan peserta untuk membuat tindak lanjut yang konkret untuk dilakukan bersama-sama dari unsur pemimpin lokal yang ada di Desa Rancamanyar. Tindak lanjut yang ingin dilakukan adalah pembenahan dalam hal "sinergitas antar lembaga dan pemimpin lokal”, berikut bentuk konkret dari sinergitas tersebut: 
1. Koordinasi dengan pihak-pihak terkait mengenai antisipasi keselamatan masyarakat atas bencana.

2. Koordinasi dan kajian lanjutan lintas stakeholder.

3. FGD rencana aksi antara pemimpin lokal, lembaga lokal, dan akademisi

4. Mengatasi dampak lingkungan, seperti permasalahan sampah, air bersih, dan limbah berbahaya di lingkungan masyarakat dan sungai citarum.

Empat rencana tersebut adalah rencana tindakan konkret atas dasar kesadaran para pemimpin lokal Desa Rancamanyar melalui pelaksanaan teknik PRA yang telah dilakukan.

Pemahaman yang baik terhadap kondisi lingkungan sosial beserta sumberdaya kelembagaannya akan meningkatkan kepekaan sosial para tokoh serta memperkuat karismanya di hadapan masyarakatnya. Percaya diri, keterampilan mengelola kesan, kepekaan sosial dan empati membuat seorang pemimpin menjadi karismatik (Singh, 2000 dalam Mathew, 2006). Karisma ini dibutuhkan seorang pemimpin untuk menambah kekuatan pengaruh dalam menggerakan masyarakat.

\section{SIMPULAN}

Berdasarkan workshop yang telah diselenggarakan dan melalui proses teknik PRA yang dilakukan bersama dengan para pemimpin lokal Desa Rancamanyar, sebenarnya para pemimpin lokal dapat dikatakan cukup memiliki inisiatif yang besar terhadap kebutuhan masyarakat Desa Rancamanyar itu sendiri, sayangnya selama ini tidak ada pihak baik dari unsur pemerintah maupun non pemerintah yang dapat memfasilitasi kepentingan masyarakat Desa Rancamanyar, sehingga para pemimpin lokal tidak tahu harus berkoordinasi dengan pihak-pihak mana saja dalam mengoptimalkan potensi dan menyelesaikan masalah yang ada di tengah-tengah masyarakat.

Dengan diselenggarakannya workshop peningkatan sensitivitas kepemimpinan lokal ini masyarakat merasa terbantu dan terfasilitasi dalam menyalurkan aspirasi dan keinginan untuk mengoptimalkan potensi yang dimiliki oleh masyarakat Desa Rancamanyar dan para pemimpin lokal membuat poin-poin tindakan konkret yang telah dijelaskan sebelumnya, dan akan ditindaklanjuti kedepannya untuk menciptakan pengelolaan sungai citarum yang berbasis masyarakat.

\section{DAFTAR PUSTAKA}


Driyamedia. 1996. Berbuat Bersama Berperan Setara. Acuan Penerapan Participatory Rural Appraisal, untuk Konsorsium Pengembangan Dataran Tinggi Nusa Tenggara. Bandung: Studio Driya Media.

LBDS. 1996. Modul Pelatihan PRA Bagi Petugas Lapangan Tingkat Kecamatan dan Tokoh Masyarakat. Proyek Konservasi dan Pengelolaan DAS Cimanuk Hulu. Garut: Lembaga Bangun Desa Sejahtera

Community Based Disaster Risk Management Course, 2006. Community Risk Assessment Modul. Bangkok: Asian Disaster Preparedness Center

Soleh Hadisutisna. 2000. Pemahaman Partisipatif Kondisi Pedesaan (PPKP), Pusat Dinamika Pembangunan Universitas Padjadjaran. Bandung: Unpad Press.

Kusnaka Adimihardja, MA, DR., Harry Hikmat, Ir., M.Si, 2001. Participatory Research Appraisal dalam Pelaksanaan Pengabdian kepada Masyarakat. Bandung: Humaniora Press.

Laporan Pelatihan TPP, 2002. Program Peningkatan Keberdayaan Petani dan Kelembagannya dalam Pengelolaan Sistem Irigasi Melalui Penggunaan Tenaga Pendamping Petani, Kerjasama Proyek Irigasi Andalan Jawa Barat dengan Fakultas Pertanian, Universitas Singaperbangsa. Karawang.

Mathews, J. 2006. Leader Relations Model: an Alternative Approach to the Traditional Process of Leadership, VISION-The Journal of Business Perspective. Vol. 10. No.4. October-December 2006.

Riggio, R.E., Reichard, R.J. 2008. The Emotional and Social Intelligences of Effective Leadership: An Emotional and Social Skill Approach, Journal of Managerial Psychology. Vol. 23 No. 2. pp. 169-185 DOI 10.1108/02683940810850808

Rubin, J. Rubin, S. 1992. Community Organizing and Development. New York: New York Press.

Ostrow, J. 1990. Social Sensitivity: A Study Of Habit And Experiance. New York: State Of New York University. 